\title{
Social carrying capacity of the Horton plains national park, Sri Lanka
}

\author{
R M W Rathnayake ${ }^{1 *}$ and U A D P Gunawardena ${ }^{2}$ \\ 1. Department of Tourism Management, Faculty of Management Studies, Sabaragamuwa University of Sri Lanka, Belihuloya. \\ 2. Department of Forestry and Environmental Science, Faculty of Applied Sciences, University of Sri Jayawardenepura, Nugegoda.
}

\begin{abstract}
The goal of this study was to investigate the social carrying capacity (SCC) of the Horton Plains National Park (HPNP). Crowding is considered as the social norm for estimating the standards for SCC. The 'normative theory' approach was applied in this study and separate social norm curves were prepared for each viewing point. Based on the hypothesis that visitor acceptability or tolerance is influenced by 'crowding', scenarios (images) with different numbers of visitors were generated for five main viewing points in the HPNP. The crowding standards for SCC were estimated by asking each respondent whether the presented scenarios were acceptable or not at each viewing point. The average visitor acceptability decreased with increasing number of visitors ('crowding'). The social norm curves were used to determine the standards. It was revealed that view points at the HPNP were crowded beyond the carrying capacity standards during weekends and public holidays. The highest carrying capacity standard was found at the Greater World's End and the least was recorded at the Chimney Pool. Therefore, the results of the present study could be applied in decision making to diversify tourism activities in order to achieve better visitor management.
\end{abstract}

Keywords: social carrying capacity, crowding, viewing points

\section{INTRODUCTION}

The carrying capacity (CC) concept is applied to parks and recreation management in order to address the relationship between visitor use and resource and social conditions. The 'CC concept' was first introduced to the field of recreation management in the mid 1930s (Manning, 1999b). The American National Park Service report on policy recommendations for parks in the California Sierras asked the question, "how large a crowd can be turned loose in a wilderness without destroying its essential qualities?" (Sumner, 1936). Over the next two decades, Wagar $(1951,1964)$ began the campaign to include $\mathrm{CC}$ concept as a major principle of recreation management.

Visitor volume and unwanted visitor behaviour can compromise a recreational experience and even lead to user conflicts (Graefe, Vaske \& Kus, 1984; Shelby, Vaske \& Heberlein, 1989; Rudell \& Gramann, 1994; Manning, 1999 a; b). So far, most research on crowding focussed on recreation in wilderness or natural areas with rather low user densities as opposed to more developed or urban recreational settings (Westover \& Collins, 1987). The perception of crowding is a complex phenomenon, which is not only influenced by user levels, but also by user conflicts, unwanted visitor behaviour and resource conditions.

\section{Social Carrying Capacity}

Social carrying capacity (SCC), often referred to as 'crowding', can be discussed as a normative concept and crowding norms are generally described as visitor-based standards that individuals and groups use for evaluating behaviour, social and environmental conditions (Donnelly, Vaske \& Shelby, 1992). Social standards are considered to be normative if there is a consensus agreement about a norm and the relative importance of the norm (Heywood, 2002). If park managers have such normative standards, they can be used for managing SCC for recreation and conservation of protected areas. 


\section{Norm Measurement Approaches}

Several approaches to measuring SCC have been developed. Visitors have been asked directly in a hypothetical context, about the maximum acceptable numbers of encounters. This numerical approach (Manning et al., 1996) referred to the evaluation of encounters of other visitors during a specific time period, mostly per day. Analyses of such data resulted in encounter norms or preference curves. Such a norm curve traces the acceptability ratings of a sample of visitors for encountering a range of groups of other visitors along a trail or at a site per time unit. Visual hypothetical approaches have been applied to measure crowding in outdoor recreation (Manning et al., 1996; Manning et al., 1999; Davis \& Lindvall 2000; Beha, Richards \& Loe, 2001). A visual presentation of crowding situations seems particularly appropriate in high use areas where it may be unrealistic to expect respondents to accurately judge the maximum number of encounters (Manning et al., 1996).

Many authors have used acceptance or preference as the evaluative response scale (Manning et al., 1996; Freimund et al., 2002). However, Manning et al. (1999) used the absolute tolerance as the evaluative response scale. Visitors were asked whether the visually presented condition was unacceptable or acceptable and whether they would shift their use to a different location or time.

A hypothetical social norm curve is shown in Figure 1 to illustrate the normative theory and methods. The norm curve traces the average acceptability rating of sample recreationists for encountering a range of groups of other visitors per day along a trail.

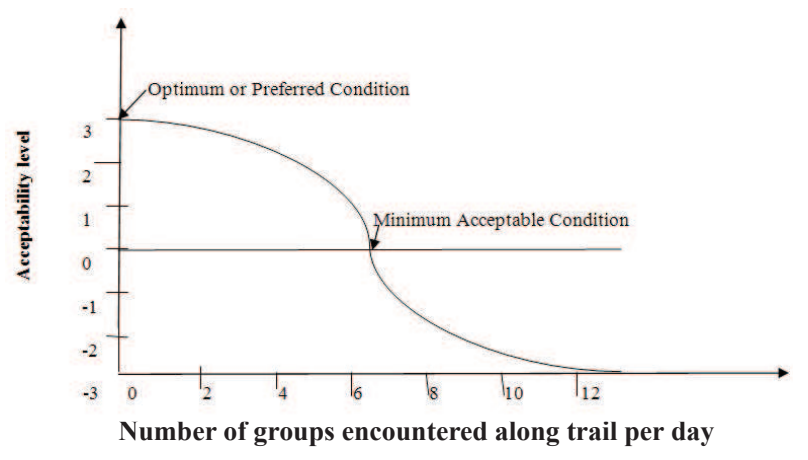

Figure 1: Hypothetical Social Norm Curve

The research on SCC has greatly expanded the knowledge on visitors' expectations, preferences and motivations for recreation opportunities. The recreation field has come to understand that visitors carry multiple expectations and motivations and that only a few may relate to user density (Cole, 2001). Also, it has been acknowledged that there is no average visitor, but rather that visitors may have widely divergent perceptions of preferred conditions for recreation settings (Manning, 1999b). Cole (2001) suggests that although density of use is not strongly correlated to the quality of experience, it may affect the nature of the experience - what it is the experience like for visitors. This greater understanding and appreciation of outdoor recreation as social behaviour has helped in moving management emphasis away from controlling usage levels for defining desired social conditions.

A few studies have been done on visitor satisfaction and nature interpretation in the HPNP in Sri Lanka and some recommendations were proposed for interpretation along the nature trail (Domroes, 2009). Gunatillake (2007) has studied the landscape and interesting features of the HPNP and had prepared a nature guide to the World's End Trail of the HPNP for enhancing the quality of visitor experience. But all these studies are not directly related to SCC.

\section{Horton Plains National Park - The Study Area}

Horton Plains National Park (HPNP) is located approximately between the latitudes $6^{\circ} 47^{\prime}$ to $6^{0} 50$ ' $\mathrm{N}$ and longitudes $80^{\circ} 46^{\prime}$ to $80^{\circ} 50^{\prime} \mathrm{E}$ (Anon, 1997).

The HPNP is situated in the southern part of Nuwara Eliya District and forms a plateau in the southeastern corner of the main ridge of Sri Lanka's central mountain massif. The HPNP forms the highest tableland in Sri Lanka, with altitudes ranging from $2100 \mathrm{~m}$ to $2300 \mathrm{~m}$. The mountain peaks of Kirigalpotta (2389 m) and Totupola Kanda $(2357 \mathrm{~m})$, the second and the third highest mountains in the island, arise from these plains. The HPNP received its name in honour of Sri Wilmot Horton, a former British Governor of Ceylon. The 3162 ha area, that forms the National Park now, was first established as a Nature Reserve in 1969, and then redesignated as a national park in 1988. The distance from the capital city-Colombo to the HPNP is $225 \mathrm{~km}$.

The HPNP has very high visitations, both by locals and foreigners, on account of its varied landscape, salubrious climate, floral and faunal heritage and an array of geomorphological attractions. It is one of those national parks in Sri Lanka where visitors are allowed to walk inside. The main attraction for the tourists is the walk to the World's End, from where a spectacular view of the tea estates and mountain ranges enveloped in mist can be seen. A "look down" from the edge of precipice is an exciting experience itself. 
In addition, the calm environment and big herds of sambar in hundreds are attractive. In 2008, 161,959 local and 10759 foreign visitors are recorded in the HPNP.

As per the existing regulations of the Department of Wildlife Conservation (DWC), the HPNP is the first National Park where visitors are allowed to walk inside the national park alone. Along the nature trail there are aesthetically pleasing and scenic viewing points/areas, and it was noticed that visitors are usually crowded at these viewing points affecting others, visitor experience. Therefore, it was found that visitors are not satisfied or disappointed on their visitor experience and that leads them to move away from the Park for other places. In addition, with crowding the fauna and flora are being affected creating negative impacts. 'Crowding' has been identified as the indicator of 'SCC' and the number of visitors at the minimum acceptability level is the standard for CC.

The objective of the present study was to determine the 'SCC' limits at five main viewing points at the HPNP i.e Red Bridge, Chimney Pool, Baker's Fall, Small World's End and Greater World's End.

\section{METHODOLOGY}

\section{Normative Approach}

As research on normative standards has progressed, several approaches to measuring norms have evolved. Traditionally, outdoor recreation-related norms have been measured using a 'numerical' or 'narrative' approach. For example, respondents might be asked to evaluate a range of encounters $(0,5,10,15$ etc.) with other groups per day along a nature trail. The derived normative data are aggregated and graphically presented to construct a 'norm curve' from which social norms might be identified.

An issue implicit in all of these measurement approaches concerns the evaluative dimension used in these questions. When respondents have been asked to evaluate a range of use levels and related impacts, the response scale has included the terminology specifying a variety of evaluative dimensions including 'acceptability', 'preference', 'pleasantness', 'desirability', 'satisfaction', and 'tolerance'.

\section{Crowding Standards}

In this study standards were established for crowding. The number of visitors seen per viewing point at any moment was a concept developed through the study to measure crowding. The 'satisfaction level' versus 'crowding' was studied. Based on the norm curve which was constructed by plotting 'satisfaction level' against 'crowding standard' were established for the visitor experience at viewing points along the nature trail.

\section{Data Collection \& Questionnaire Survey}

The visitors to the park were first divided into two categories i.e. local and overseas visitors. The primary data were collected from a field questionnaire survey. Visitors were interviewed at five viewing points (Red Bridge, Chimney Pool, Baker's Fall, Greater World's End and Small World's End) individually. The questionnaire was designed to collect the information directly and it consisted of 09 sections. Information on number of visitors seen and the 'satisfaction level' on 'crowding' at each viewing point were collected in the nine sections. Six acceptable levels for their satisfaction were included in the questionnaire with hypothetical visual presentations with visitors (i.e. HA- Highly Acceptable, A-Acceptable, FA- Fairly Acceptable, FUA- Fairly Unacceptable, UAUnacceptable, HUA-Highly Unacceptable).

In the pilot surveys it was revealed that there was no significant difference in the answers given by the foreign visitors from the locals. Based on simple random sampling (using random number tables) at each viewing point 100 visitors were interviewed showing seven hypothetical visual scenarios (in printed form and model slide presentation) asking their acceptability for visitor satisfaction against crowding.

The questionnaire survey was carried out from 07.00 am to $05.00 \mathrm{pm}$ during the period from January 2008 to December 2008. The survey was conducted on weekdays, public holidays and weekends. This questionnaire was pre-tested with 15 visitor groups for clarifying feasibility of data collection. The unusual information which was given by some visitors was not used for norm curve construction.

The six acceptable levels were numerically numbered (i.e. HA-Highly Acceptable (+1.0), A-Acceptable $(+0.5)$, FA-Fairly Acceptable (+0.25), FUA-Fairly Unacceptable (-0.25), UA-Unacceptable (-0.5), HUAHighly Unacceptable (-1.0) when the graph (Social Norm Curve) was plotted with satisfaction level against hypothetical visual crowding.

\section{RESULTS}

Table 1 shows that the acceptability levels have decreased with the increasing numbers at Red Bridge. The highest acceptability for visitor satisfaction was found at 
less than ten visitors at this viewing point. Whereas, unacceptability levels were found at more than twenty visitors.

The number of visitors against the sum of acceptability was plotted and the social norm curve was constructed for Red Bridge (Figure 3). The maximum acceptability level was found, if the Red Bridge was crowded by less than 10 visitors, and the acceptability level had drastically decreased when the visitor number was more than ten. The maximum unacceptability level was recorded if the viewing point was crowded by more than forty one visitors. The minimum acceptability level was between 20 and 30 visitor group size. According to Figure 3, the norm curve also crosses the acceptability level at twenty two visitors at the viewing point, which indicates the SCC standard for the Red Bridge. Except the Chimney Pool, the lowest SCC is recorded at the Red Bridge.

Table 1: Acceptability levels with range of visitors at each main viewing point of the HPNP

\begin{tabular}{|c|c|c|c|c|c|}
\hline \multirow{2}{*}{$\begin{array}{c}\text { No. of Visitors } \\
\text { (Scenarios) }\end{array}$} & $\begin{array}{c}\text { Red } \\
\text { Bridge }\end{array}$ & $\begin{array}{c}\text { Chimney } \\
\text { Pool }\end{array}$ & $\begin{array}{c}\text { Baker's } \\
\text { Fall }\end{array}$ & $\begin{array}{c}\text { Small } \\
\text { World's } \\
\text { End }\end{array}$ & $\begin{array}{c}\text { Greater } \\
\text { World's } \\
\text { End }\end{array}$ \\
\hline$(0-5)$ & 1 & 1 & 1 & 1 & 1 \\
\hline$(6-10)$ & 1 & 0.90 & 1 & 0.97 & 0.98 \\
\hline$(11-15)$ & 0.515 & 0.04 & 0.88 & 0.94 & 0.96 \\
\hline$(16-20)$ & 0.072 & -0.308 & 0.76 & 0.85 & 0.92 \\
\hline$(21-30)$ & -0.37 & -0.605 & 0.49 & 0.63 & 0.66 \\
\hline$(31-40)$ & -0.74 & -1 & 0.13 & -0.19 & 0.2 \\
\hline$(41-50)$ & -1 & - & -0.69 & -0.67 & -0.60 \\
\hline$(51-60)$ & - & - & -1 & -1 & -0.87 \\
\hline$(61-70)$ & - & - & - & - & -1 \\
\hline
\end{tabular}

The acceptability levels have decreased with the increasing number of visitors at Chimney Pool as shown in Table 1. The greatest acceptability for visitor satisfaction was found at less than ten visitors at the viewing point. The acceptability levels had decreased dramatically between the visitor group sizes $5-10$ and $11-15$, whereas, afterwards the levels had decreased gradually. It was revealed that the acceptability level decreases rapidly when the number of visitors increases at Chimney Pool.

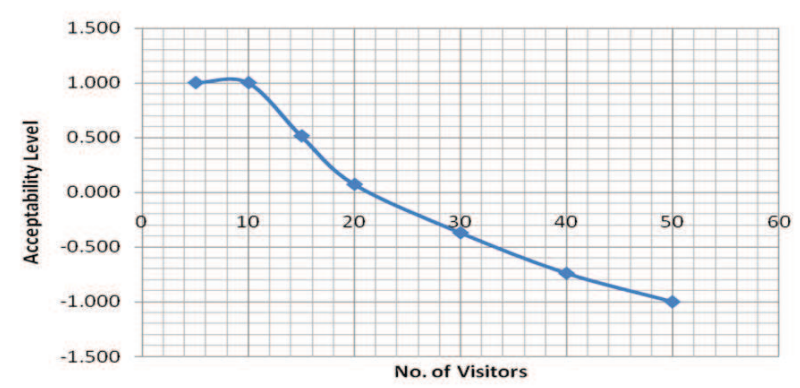

Figure 3: Social Norm Curve for Red Bridge
The social norm curve crosses the acceptability level at fifteen visitor limit reflecting the SCC standard for the Chimney Pool viewing point (Figure 4).

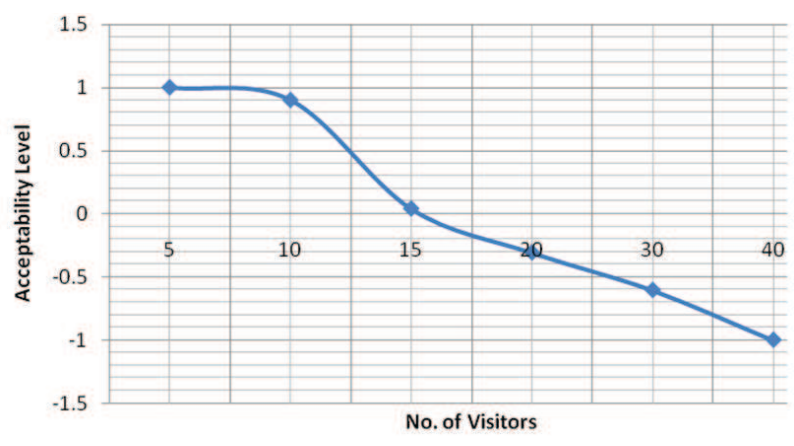

Figure 4: Social Norm Curve for Chimney Pool

At Baker's Fall only ninety seven visitors answered from the 100 visitors interviewed. The greatest acceptability for visitor satisfaction was found at less than ten visitors at this viewing point. The acceptability levels decreased gradually from visitor number size $11-15$ to $31-40$. Meanwhile, the acceptability drastically decreased from visitor group size $31-40$ to $41-50$.

The SCC standard for the Baker's Fall is forty two according to the social norm curve. (Figure 5)

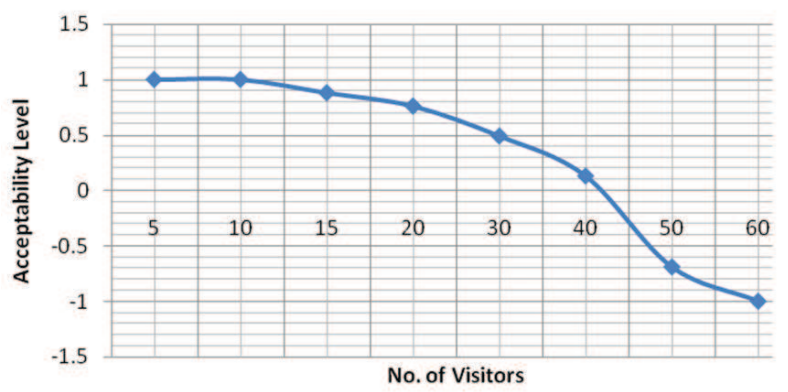

Figure 5: Social Norm Curve for Baker's Fall

As at other viewing points discussed the acceptability levels decreased with the increasing number of visitors at Small World's End. Here too, 100 visitors were interviewed, although only ninety nine responded. It revealed that the acceptability level has decreased gradually from less than five visitor group to less than thirty visitor group and after that it had drastically decreased.

The social norm curve crosses the minimum acceptability level between visitor group size thirty and forty (Figure 6) indicating that the SCC standard for Small World's End is 37. 


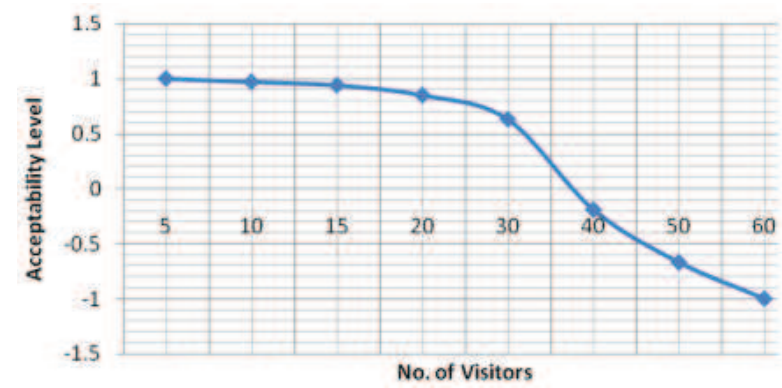

Figure 6: Social Norm Curve for Small World's End

Table 1 shows that the acceptability levels with number of visitors have decreased with increasing number of visitors at the Greater World's End showing similar pattern as other viewing points discussed. Hundred visitors were interviewed, and all the visitors answered. The acceptability for visitor satisfaction was found at less than thirty visitors at this viewing point, and after that visitor unacceptability had increased.

The acceptability level decreases steadily from less than five visitor group to less than thirty visitor group and after that it decreases drastically.

According to Figure 7, the norm curve crosses the acceptability level at forty three visitors at the viewing point which indicates the SCC standard for Greater World's End.

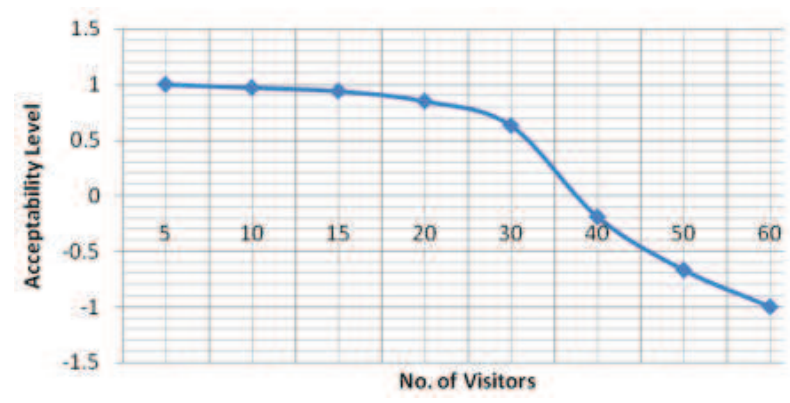

Figure 7: Social Norm Curve for Greater World's End

Table 2 shows the determined crowding standards for the five viewing points discussed above. The highest visitor carrying capacity was found at the Greater World's End and the least was recorded at the Chimney Pool. The SCC levels at Baker's Fall and Greater World's End are almost equal. These visitor acceptable levels could be considered as the crowding standards for each viewing point. Beyond these determined crowding standards for each view point, the nature of visitor experience is negatively affected and their visitation goals are interefered. That may cause displacement of visitors (visitors preferring to go to another place) to sites outside the HPNP i.e. within the park or change of site from World's End to Chimney Pool.
The mean number of visitors at each viewing point was calculated randomly by counting the number of visitors. The mean number of visitors at Baker's Fall, Small World's End and Greater World's End are greater than the minimum acceptable conditions (standards) at each viewing point. It was also noticed that there were limited number of visitors at the view points on working days. The viewing points, Red Bridge and Chimney Pool were not at the minimum acceptable conditions. It could be proposed to limit the number of visitors to the viewing points i.e. Baker's Fall, Small World's End and Greater World's End, especially on public holidays and weekends.

Table 2: Crowding standards for viewing points

\begin{tabular}{|l|c|c|}
\hline \multicolumn{1}{|c|}{ View Point } & $\begin{array}{c}\text { Number of visitors } \\
\text { at each minimum } \\
\text { acceptable } \\
\text { condition }\end{array}$ & $\begin{array}{c}\text { Mean number of } \\
\text { visitors at view } \\
\text { points (week - } \\
\text { ends and public } \\
\text { holidays) }\end{array}$ \\
\hline Red Bridge & 22 & 13 \\
\hline Chimney Pool & 15 & 15 \\
\hline Baker's Fall & 42 & 43 \\
\hline Small World's End & 37 & 41 \\
\hline Greater World's End & 43 & 48 \\
\hline
\end{tabular}

\section{DISCUSSION}

The visitor numbers, proximity to others and mix of users influences the respondents' decision to shift their use and acceptability levels at each viewing point. In addition, unwanted visitor behaviour due to crowding may affect the visitor acceptability.

The social norm curves clearly showed that the visitor acceptability levels have gone down with increasing number of visitors at each view point. Except the Red Bridge and the Chimney Pool other view points are beyond the visitor carrying capacity levels especially on weekends and public holidays because HPNP gets more visitors during such time.

Visitor infrastructure such as viewing decks have been constructed at viewing points at Greater World's End, Small World's End and Baker's Fall to accommodate more visitors and for visitors to spend more time there. There are no viewing decks at Chimney Pool and Red Bridge to accommodate more visitors, and as a result visitors do not stay long at these viewing points.

The factors and theories with regard to crowding perceptions were thought to be useful in defining a crowding norm for recreation areas and, indicators and 
standards could also be formulated. This multivariate elicitation of crowding norms has been successful because of a very specific tolerance type question, as formulated in the referendum style conjoint question, combined with the application of digitally calibrated images, which carefully followed a predefined design plan. With this application, it is documented that the phenomenon of social carrying capacity is also highly relevant for planning and implementation of recreational areas like national parks. Therefore the calculated crowding standards for the view points at the HPNP could be applied for visitor management.

Extensive research and management experience over the last thirty years have revealed significant problems and deficiencies with application of $\mathrm{CC}$ model to recreation management issues. The key concern was that it framed the problem of managing recreation in relation to managing levels of use. Restricting visitor use is a poor method of managing resource impacts because, in most situations, a little use causes considerable impact and further increases in use levels have less and less additional effect on the natural environment (Cole, 1987; Wight, 1998; Leung \& Marion, 2000; Newsome, Moore \& Dowling, 2002). All recreation use causes some changes in the natural environment, so impacts from recreation use only becomes damaging when there is some judgment about what conditions ought to be in a particular area - it is a value judgment that must be defined by park managers and the public (Wagar, 1974; Wight,1998). Managing recreation use is a socio-political process that involves choices about values and how those values will be distributed across the landscape and among users (Stankey, 1997). It is a social rather than a technical problem, so the focus of new decision making models has shifted towards what is most important: defining desired resource conditions and visitor experiences.

The determination of visitor carrying capacity or SCC determination is very important for visitor services and ecotourism planning processes. Crowding may interfere the goal of the visitor, i.e. the visitor's recreational, educational or enjoyment. The impacts change the nature of recreation experiences available. Visitors may get attracted to other national parks, wilderness areas or recreational areas. In addition, they may shift the recreational product. For example, some visitors may go along the Totupolakanda trail instead of going along the World's End trail in the HPNP. The question is whether the change is accepted by the park managers and existing legislation.

The CC concept has primarily failed to provide the needed framework for managing recreational use. The limits of acceptable change (LAC) concept deals with a significantly different question: ' What resource and social conditions are appropriate (or acceptable), and how do we attain those conditions?' This question represents a substantially different approach to thinking about recreational use questions, yet is actually more closely aligned with the principal job of recreation managers protecting the values for which an area was established than the CC paradigm (Stankey et al., 1985).

Currently, visual approaches have been developed for measuring crowding and other outdoor recreation related norms have been developed. Computer software have been used to edit and provide photographs depicting a range of use levels, environmental impacts and visitor satisfaction at Arches National Park in USA (Hof et al., 1994; Manning et al., 1995).

Manning et al. (1997) applied the normative approach to estimate the crowding standards along the carriage road at the Acadia National Park in the United States, where visitors were shown six scenarios digitally (six ranges of visitor uses), and asked their acceptability on a scale of -4 (very unacceptable) to +4 (very acceptable). However, in the present study the range of scale used was from -1 (highly unacceptable) to +1 (highly acceptable).

In addition to the normative theory approach, indifference curve analysis has been recently adapted to examine the visitor carrying capacity in the Arches National Park (Lawson \& Manning, 2000; 2001b; 2002a). Stated choice analysis represents another research approach to quantify CC related values and trade-off inherent in park and wilderness management. Recently, stated choice modelling has been adapted to $\mathrm{CC}$ analysis and applied at Denali National Park (Lawson \& Manning 2001a; 2002b) and Yosemite National Park (Newman, Marion \& Cahill, 2001; Newman, Manning \& Valliere, 2002).

\section{CONCLUSION}

According to the results, crowding is not a significant issue at the HPNP, although during the weekend and holidays crowding could exceed the crowding standards that resulted from the study. The 'World's End' attraction and scenic landscape are the major attractions of the HPNP. This site is also popular among visitors as a picnic site for day outings. National Parks have been charged with the dual mandate of providing quality recreation opportunities and protecting park resources. Protected area managers in many parts of the world share similar responsibilities. Crowding affects visitor satisfaction as well as the natural resource base. Therefore, it is recommended to maintain the estimated standards for visitor services planning in the HPNP.

Within a national park, visitor impacts could be seen under the categories of trail impacts, litter impacts, water 
impacts, wildlife impacts, illegal collecting impacts, off road driving, visitor crowding and conflicts mainly due to crowding. These impacts could be minimized by management actions. The LAC as a planning system is viewed as a way for managers to confront and resolve the complex issues of managing visitors not only to provide the experiences they seek, but to deal with the problems of their social and biophysical impacts. Therefore, a visitor impact monitoring plan has to be implemented at the HPNP. However, by improving, visitor facilities and services this park would receive more visitors and further crowding could result.

Since limiting the number of visitors to the park is not practical, it is proposed to diversify the tourism activities within the park. At the moment, the viewing points of World's End and Baker's Falls are widely used and located within the $9 \mathrm{~km}$ long existing nature trail. Therefore, it is recommended to diversify tourism activities within the park rather than promoting the existing nature trail. For example, the abandoned scenic and wildernic Totupola Kanda and Kirigalpoththa trails could be rehabilitated and opened for the visitors. In addition, the exisiting economic assessments have revealed that the Park has been undervalued, and therefore the Park entrance fee could be increased upto a certain extent to maximize the revenue to the park. However, proper economic studies have to be conducted prior to the implementation of the new entry fee structure.

\section{References}

1. Anon., 1997. Wetland site report and conservation management plan for Horton Plains National Park. Colombo: Central Environmental Authority, Sri Lanka.

2. Behan, J. R., Richards, M. T. \& Loe, M. E., 2001. Effects of tour jeeps in a wildland setting on non-motorized recreational benefits. Journal of Park and Recreation Administration, 19(2), pp. 1-19.

3. Cole, D., 1987. Research on soil and vegetation in wilderness: A state of knowledge review. In: Proceedings of the National wilderness research conference: Issues, state of knowledge, future directions (pp. 135-177). Ogden, USA: Department of Agriculture.

4. Cole, D. N., 2001. Visitor use density and wilderness experiences: a historical review. In: W.A. Freimund \& D.N. Cole (Comps.), Visitor use density and wilderness experience, Proceedings RMRS-P-20. Ogden: U.S. Department of Agriculture, Rocky Mountain Research Station, pp.11-20.
5. Davis, J. B. \& Lindvall, M., 2000. Standards of quality for river use within the Fort Niobrara Wilderness Area. In: D. Cole, S.F. McCool, W.T. Borrie \& J. O'Loughlin (eds). Willingness visitors, experience, and visitor management. Proceedings RMRS-P:Vol-4. Ogden. UT:USDA Forest Service, Rocky Mountain Research Station. pp. 265-273.

6. Domroes, M., 2009. Visitor satisfaction with Horton Plains National Park and Proposal for an Interpretive Nature Trail. In: Traversing No Man's Land. Colombo: Godage Int. Publishers. Ch. 20.

7. Donnelly, M., Vaske, J. \& Shelby, B., 1992. Measuring backcountry standards in visitor surveys. Defining wilderness quality: The role of standards in wilderness management. USDA Forest Service, General Technical Report PNW-305, pp. 38-52.

8. Freimund, W. A., Vaske, J. J., Donnelly, M. P. \& Miller, T. A., 2002. Using video surveys to access dispersed backcountry visitors' norms. Leisure Sciences, 24, pp. 34962.

9. Graefe, A. R., Vaske, J. J. \& Kuss, F. R., 1984. Social carrying capacity: an integration and synthesis of twenty years of research. Leisure Sciences 6(4), pp. 365-431.

10. Gunatillake, C.V. S., 2007. A Nature Guide to the World's End Trail, Horton Plains. Department of Wildlife Conservation, Sri Lanka

11. Heywood, J. I., 2002. The cognitive and emotional components of bahaviour norms in outdoor recreation. Leisure Sciences, 24, pp. 271-81.

12. Hof, M., Hammit, J., Ress, M., Belnap, J., Poe, N., Lime, D. \& Manning, R., 1994. Getting a handle on visitor carrying capacity- a pilot project at Arches National Park. Park Service, 14, pp.11-13.

13. Lawson, S. \& Manning H., 2000. Crowding versus access at Delicate Arch, Arches National Park: an indifference curve analysis. In: Proceedings of the Third Symposium on Social Aspects and Recreation Research, Arizona State University, pp.135-43.

14. Lawson, S. \& Manning H., 2001a. Crossing experiential boundaries: visitor preferences regarding tradeoffs among social, resource, and managerial attributes of the Denali wilderness experience. The George Wright Forum,18(3), pp.10-27.

15. Lawson, S. \& Manning H., 2001b. Evaluating multiple dimensions of visitors' tradeoffs between access and crowding at Arches National Park using indifference curve analysis. In: Proceedings of the 2000 Northeastern Recreation Research Symposium, 2-4 April 2000. U.S. Department of Agriculture Forest Service, Northeastern Research Station, pp.167-75. 
16. Lawson, S. \& Manning H., 2002a. Solitude versus access: a study of tradeoffs in outdoor recreation using indifference curve analysis. Leisure Sciences 23, pp. 179-91.

17. Lawson, S. \& Manning H., 2002b. Tradeoffs among social resource, and management attributes of the Denali wilderness experience: A contextual approach to normative research. Leisure Sciences. 24, pp. 297-312.

18. Leung, Y. F., \& Marion, J., 2000. Recreation impacts and management in wilderness: A state-of-knowledge review. In: Wilderness Science in a Time of Change ConferenceVolume 5: Wilderness Ecosystems, Threats, and Management. Ogden, UT: USDA Forest Service, Rocky Mountain Research Station.

19. Manning, R. 1999a. Crowding and carrying capacity in outdoor recreation: From normative standards to standards of quality. In: Edgar L. Jackson \& T. L. Burton (eds.), Leisure Studies: Prospects For The Twenty-First Century. State College, PA: Venture Publishing.

20. Manning, R.E., 1999b. Studies in outdoor Recreation, Search and Research for Satisfaction. Oregon: State University Press.

21. Manning, R., Ballinger, N., Valliere, W., Wang, B. \& Jacobi, C., 1997. Acadia National Park Carriage Road Study: Phase III Research. U. S. National Park Service Technical Report NPS/NESORNR/NRTR/98-1. Boston: National Park Service. pp. 57-72.

22. Manning, R., Lime, D., Hof, M. \& Freimund, W. A., 1995. The visitor experience and resource protection process: the application of carrying capacity to Arches National Park. The George Wright Forum 12(3), pp. 41-55.

23. Manning, R. E., Lime, D. W., Freimund, W. A. \& Pitt, D. G., 1996. Crowding norms at front country sites:A visual approach to setting standards of quality. Leisure Sciences, 18, pp. 39-59.

24. Manning, R. E., Valliere, W. A., Wang, B. \& Jacobi, C., 1999. Crowding norms: alternative measurement approaches. Leisure Sciences 21, pp. 97-115.

25. Newman, P., Manning, R. \& Valliere, W., 2002. Intergrating resource, social and managerial indicators of quality into carrying capacity decision-making Intergrating resource, social and managerial indicators of quality into carrying capacity decision-making. In: Proceedings of the 2001 Northeastern Recreation Research Symposium. General Technical Report NE-289. U.S. Department of Agriculture Forest Service. Northeastern Research Station, pp. 23338.
26. Newman, P.J., Marion \& Cahill, K., 2001. Intergrating resource, social and managerial indicators of quality into carrying capacity decision-making. The George Wright Forum, 18(3), pp. 28-40.

27. Newsome, D., Moore, S. \& Dowling, R., 2002. Natural Area Tourism: Ecology, Impacts and Management. Clevedon: Channel View Publications.

28. Rudell, E.J. \& Gramann, J.H., 1994. Goal orientation, norms, and noise-induced conflict among recreation area users. Leisure Sciences 16, pp. 93-104.

29. Shelby, B., Vaske, J.J. \& Heberlein, T.H., 1989. Comparative Analysis of Crowding in Multiple Locations:Results from Fifteen Years of Research. Leisure Sciences 11(4), pp. 26991.

30. Stankey, G., 1997. Institutional barriers and opportunities in application of the Limits of Acceptable Change. In: Proceedings - Limits of Acceptable Change and Related Planning Processes: Progress and Future Directions. Ogden, UT: USDA Forest Service, Intermountain Research Station. pp. 10-15.

31. Stankey, G. H., Cole, D. N., Lucas, R. C., Petersen, M. E. \& Frissell, S. S., 1985. The Limits of Acceptable Change (LAC) system for wilderness planning. Gen. Tech. Report INT-176, USDA Forest Service Intermountain Forest and Range Experiment Station, Ogden, UT.

32. Sumner, E., 1936. Special Report on a Wildlife Study in the High Sierra in Sequoia and Yosemite National Parks and Adjacent Territory Washington, D.C.: U.S. National Park Service Records, National Archives.

33. Wagar J., 1951. Some major principles in recreation land use planning. Journal of Forestry, 49(6), pp. 431-35.

34. Wagar, J., 1974. Recreational carrying capacity reconsidered. Journal of Forestry, 72, pp. 274-78.

35. Wagar, J.A., 1964. The carrying capacity of wild lands for recreation. Forest Science monograph 7. Washington, D.C.: Society of American Foresters

36. Westover, T.N. \& Collins, J.R., 1987. Perceived crowding in recreation settings: an urban case study, Leisure Sciences 9, pp. 87-99.

37. Wight, P., 1998. Tools for sustainability analysis in planning and managing tourism and recreation in the destination. C. M. Hall, \& A. A. Lew (eds.), Sustainable tourism: A geographical perspective. Harlow, Essex, UK: Addison Wesley Longman. pp. 75-91. 